\title{
FLUXO DE NUTRIENTES EM FLORESTA OMBRÓFILA DENSA DAS TERRAS BAIXAS NO LITORAL DO PARANÁ
}

\author{
Lígia Carla de Souza ${ }^{1}$, Renato Marques ${ }^{2}$ \\ ${ }^{1}$ Eng $^{\mathrm{a}}$ Florestal, Dra ${ }^{\mathrm{a}}$, Curitiba, PR, Brasil - ligiaengflor@yahoo.com.br \\ ${ }^{2}$ Eng. Florestal, Dr., Depto. de Solos e Engenharia Agrícola, UFPR, Curitiba, PR, Brasil - rmarques@ufpr.br
}

Recebido para publicação: 12/05/2008 - Aceito para publicação: 21/05/2009

\begin{abstract}
Resumo
A Floresta Estadual do Palmito é um remanescente do Bioma Mata Atlântica, com vegetação característica de Floresta Ombrófila Densa das Terras Baixas e encontra-se, atualmente, composta por diferentes fases da sucessão secundária. Essa formação florestal ocorre sobre Espodossolos arenosos e de baixa fertilidade, sendo a ciclagem de nutrientes fundamental para a sustentabilidade do ecossistema. Este trabalho teve por objetivo gerar informações sobre a entrada de nutrientes em tipologias florestais representativas da Floresta Atlântica no litoral do Paraná. As parcelas estudadas foram selecionadas para representar três tipologias florestais com diferenças em idade, diversidade florística e histórico de uso da terra. Para o monitoramento da precipitação total, foi instalado um pluviômetro em clareira próxima às parcelas de estudo. Em cada tipologia florestal, foram instalados 5 coletores de precipitação interna. As amostragens das soluções foram realizadas a cada 21 dias, de julho de 2000 a dezembro de 2004. A entrada de sódio e cálcio nos ecossistemas através da precipitação foi expressiva, sendo também marcante para potássio e magnésio. A ordem decrescente de entrada de elementos minerais através da precipitação externa foi $\mathrm{Na}>\mathrm{Ca}>\mathrm{Mg}>\mathrm{K}>\mathrm{NO}_{3}$, e $\mathrm{Na}>\mathrm{Ca}>\mathrm{K}>\mathrm{Mg}>\mathrm{NO}_{3}$ para precipitação interna, caracterizando uma forte influência de aerossóis marinhos na composição química das precipitações.

Palavras-chave: Floresta Atlântica; biogeoquímica; precipitação interna.
\end{abstract}

\begin{abstract}
Nutrient fluxes in Lowland Dense Ombrophylous Forest in the coast of Paraná. The Palmito State Forest is a remnant of the Atlantic Rainforest ecosystem, with a typical vegetation of the Lowland Dense Ombrophylous Forest that is currently composed by different phases of secondary succession. This forest formation occurs on sandy and low fertility Spodosols, and the nutrient cycling is essential for the sustainability of this ecosystem. This work was carried out aiming to generate data that can help the understanding of nutrients input in Atlantic Rainforest ecosystems on the coastal region of Parana. The study plots were selected to represent three forest typologies differing in age, flora diversity and history of land use. For bulk precipitation monitoring, a pluviometer was installed in an open area close to the forest plots. In each plot they were installed 5 throughfall collectors. Sampling of solutions was carried out every 21 days, from July of 2000 to December of 2004. The input of sodium and calcium in the ecosystems through precipitation was very expressive, and a little less for potassium and magnesium. The decreasing order of mineral elements input through the external precipitation was $\mathrm{Na}>\mathrm{Ca}>\mathrm{Mg}>\mathrm{K}>\mathrm{NO} 3$, and $\mathrm{Na}>\mathrm{Ca}>\mathrm{K}>\mathrm{Mg}>\mathrm{NO} 3$ for internal precipitation, characterizing a high influence of marine aerosols on the chemical composition of precipitations. Keywords: Atlantic Forest; biogeochemistry; throughfall.
\end{abstract}

\section{INTRODUÇÃO}

O estado do Paraná conserva, em seu litoral, remanescentes do bioma Mata Atlântica, com a ocorrência de diversos ecossistemas florestais que se distinguem em porte e composição florística, em função da sua posição quanto ao relevo, aos fatores climáticos, ao tipo de solo e à altitude, entre outros fatores. Entre os ecossistemas que compõem a Floresta Atlântica, encontra-se a Floresta Ombrófila Densa das Terras Baixas (FODTB), ou Floresta Atlântica de Planície, situada sobre solos pertencentes à classe 
dos Organossolos, Espodossolos e Neossolos Quartzarênicos, sendo que sua florística está intimamente ligada ao tipo de solo sobre o qual se desenvolve (RODERJAN et al., 2002).

Além do tipo de solo, a ciclagem de nutrientes é de grande importância para a sustentabilidade da floresta, ocorrendo em diferentes compartimentos e envolvendo fluxos de entrada e saída de nutrientes. Entre esses fluxos, o da água de precipitação que atinge a cobertura florestal contribui significativamente para a nutrição florestal.

As águas da chuva trazem consigo elementos minerais e orgânicos que se encontram suspensos na atmosfera e, ao atravessar o dossel florestal, contribuem para a absorção foliar de alguns nutrientes e também para a lavagem e/ou lixiviação de elementos essenciais às plantas, os quais são transferidos ao solo e, posteriormente, às águas superficiais e subsuperficiais, podendo ser novamente absorvidos pelas árvores (BLUM, 1978; HAAG, 1985; POGGIANI, 1992).

Apesar da importância desses fluxos para a manutenção das florestas, poucos estudos foram realizados sobre o papel da precipitação na entrada de nutrientes na Floresta Atlântica (ARCOVA; CICCO, 1987; BRITEZ, 1994; SCHEER, 2006; PROTIL, 2006).

De maneira a gerar informações importantes para a compreensão da dinâmica biogeoquímica em ecossistemas de Floresta Atlântica, na Planície Pleistocênica do litoral paranaense, este estudo teve como objetivo estudar o aporte de nutrientes ao solo através das precipitações externa e interna à floresta, sendo esta última coletada em diferentes tipologias florestais, de maneira a avaliar o efeito da vegetação sobre tais fluxos de nutrientes.

\section{MATERIAL E MÉTODOS}

\section{Caracterização da área de estudo}

Localização e clima

A área de estudo encontra-se dentro da Floresta Estadual do Palmito, unidade de conservação com uma área de 530 ha inseridos sobre a planície costeira. Foi criada através do Decreto $n^{\circ} 4.493$, de 17/06/1998, sendo administrada pelo Instituto Ambiental do Paraná (IAP). Está localizada na rodovia PR047, município de Paranaguá (PR), entre as coordenadas $25^{\circ} 34^{\prime} / 25^{\circ} 34^{\prime} 40^{\prime \prime}$ de latitude sul e $48^{\circ} 33^{\prime} 44^{\prime \prime} / 48^{\circ} 31^{\prime} 12^{\prime \prime}$ de longitude oeste de Greenwich (Figura 1).

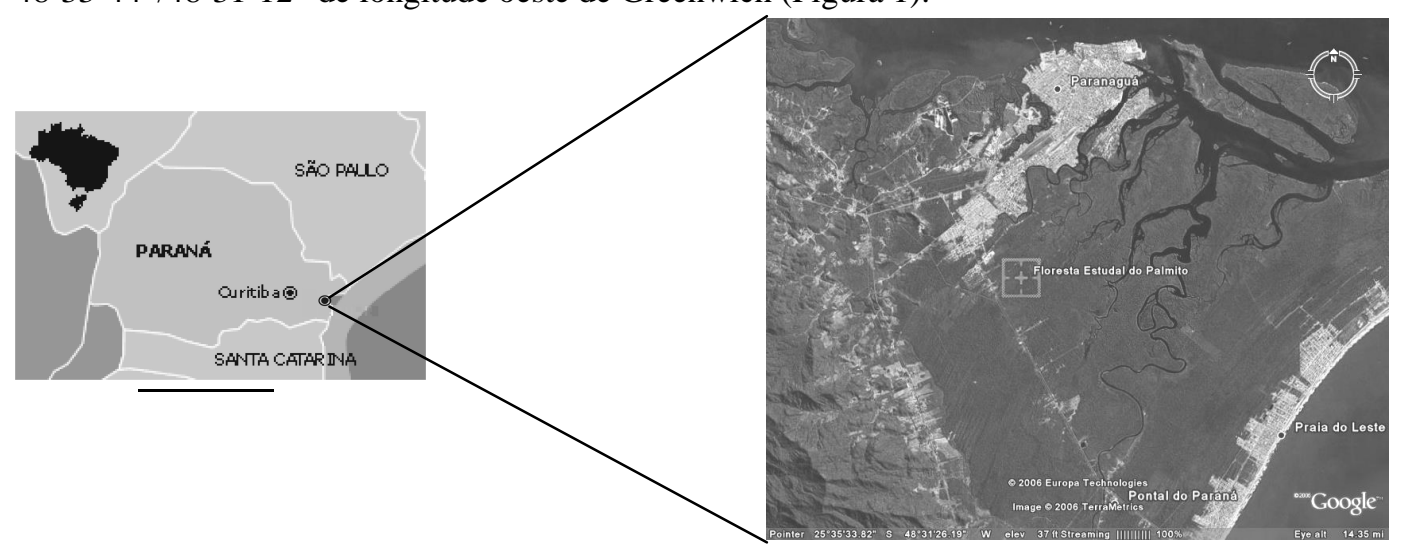

Figura 1. Localização da área de estudo - Floresta Estadual do Palmito, Paranaguá (PR).

Figure 1. Location of the study area - Palmito State Forest, Paranagua (PR).

O clima da região é tipo Af, segundo classificação de Köppen, caracterizado como tropical chuvoso, com temperatura média anual de $21{ }^{\circ} \mathrm{C}$, sem estação seca, isento de geada e com precipitação variando entre 2.000 e $3.000 \mathrm{~mm}$ (IAPAR, 1978). A altitude das áreas varia entre 4 e $6 \mathrm{~m}$ a.n.m.

Dados climáticos de 1976 a 2006 de Paranaguá, fornecidos pelo INMET, mostram que nos últimos 30 anos a temperatura média anual foi de $21,5^{\circ} \mathrm{C}$, sendo a média das temperaturas máximas igual a $25,2{ }^{\circ} \mathrm{C}$, registrada nos meses de janeiro e fevereiro, e as médias das mínimas registradas de $17,2{ }^{\circ} \mathrm{C}$, no mês de julho. Para a precipitação, o total anual médio foi de 2240,1 mm, sendo janeiro, fevereiro e março 
os meses mais chuvosos. Junho e agosto apresentam as menores médias. A umidade relativa média apresentou pequenas variações, permanecendo em torno de $85 \%$ durante todo o período (Figura 2).

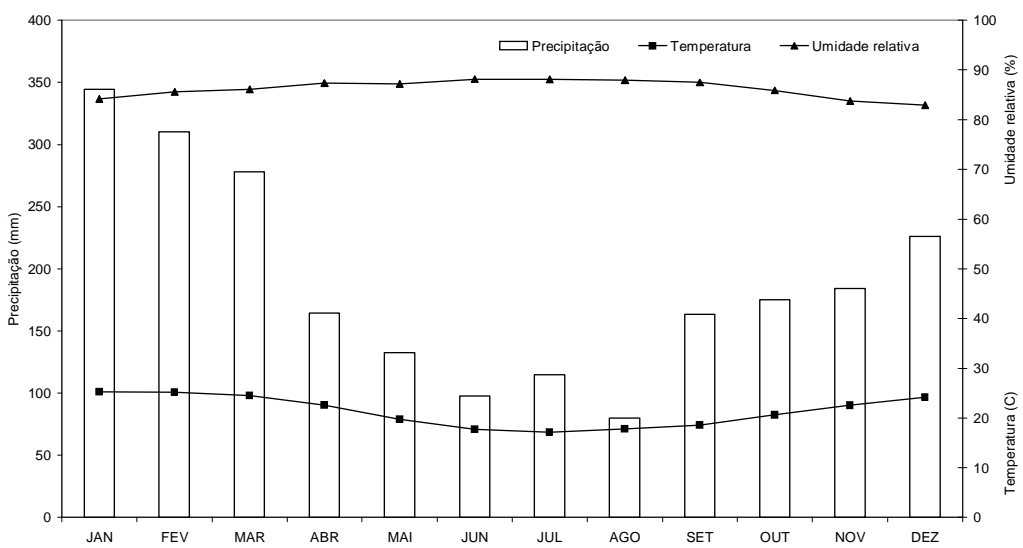

Fonte: Instituto Nacional de Meteorologia INMET (2006)

Figura 2. Variações médias da precipitação, temperatura e umidade relativa ocorridas entre 1976 e 2006, em Paranaguá (PR).

Figure 2. Average variations of precipitation, temperature and relative humidity between 1976 and 2006, Paranagua (PR).

Vegetação

A vegetação original da área de estudo é classificada como Floresta Ombrófila Densa das Terras Baixas (IBGE, 1992). Atualmente, como resultado de intervenções antrópicas, a vegetação encontra-se em diferentes estágios sucessionais. Na área estudada, foram selecionadas três tipologias florestais, caracterizadas por diferentes idades e estruturas fitossociológicas, denominadas de Tipologia Florestal Inicial - TF INI (22 anos), Tipologia Florestal Média - TF MED (35 anos) e Tipologia Florestal Avançada - TF AVA (mais de 60 anos), sendo as idades estimadas para o ano de 2004. Uma descrição das principais características das três tipologias é apresentada a seguir.

A Tipologia Florestal Inicial (TF INI) teria sofrido dois cortes rasos sucessivos, sendo o último realizado no ano de 1982. Vestígios (pequenos fragmentos de carvão) indicam que foram realizadas queimadas nessa área, e sabe-se que foram realizados cultivos agrícolas, como mandioca (Manihot esculenta Crantz), por cerca de 4 anos. Apresenta fisionomia herbáceo/arbustiva de porte baixo, com cobertura vegetal variando de fechada a aberta, com ausência de sub-bosque. Apresenta espécies lenhosas com distribuição diamétrica de pequena amplitude. As epífitas, presentes com baixa diversidade, são representadas principalmente por liquens, briófitas e pteridófitos. Essa tipologia apresenta uma camada de serapilheira fina pouco decomposta, sendo que em alguns pontos o solo encontra-se descoberto, ou coberto por liquens fruticolosos (Cladonia sp.). A diversidade biológica é variável, com poucas espécies arbóreas ou arborescentes, podendo apresentar plântulas de espécies características de outros estágios. Apresenta, ainda, abundância de espécies pioneiras. Das espécies encontradas, são quatro as que mais se destacam nessa tipologia: a caúna (Ilex theezans), vermelho (Ternstroemia brasiliensis), jacarandálombriga (Andira anthelminthica) e canela-lageana (Ocotea pulchella).

A Tipologia Florestal Média (TF MED) teria sido cortada apenas uma vez no final dos anos 60 , sendo também cultivada por curto período e depois abandonada. Apresenta-se bem mais desenvolvida que a TF INI, com fisionomia arbórea e/ou arbustiva predominando sobre a herbácea, podendo ser observada uma estratificação do dossel, como também presença de sub-bosque. A cobertura arbórea varia de aberta a fechada, com ocorrência de indivíduos emergentes. Nessa tipologia, as epífitas aparecem em maior número de indivíduos e de espécies quando comparada à TF INI, devido ao sombreamento e umidade característicos dessa tipologia. A serapilheira é presente e significativa, formando camadas de espessuras variadas, de acordo com as estações do ano e a localização. A TF MED apresenta uma diversidade biológica um pouco superior à TF INI, sendo que as espécies que se destacam são caúna (Ileex theezans), vermelho (Ternstroemia brasiliensis), capororocão (Rapanea umbellata) e papagoela (Gomidesia schauerina). O que chama a atenção nessa tipologia é a presença da cupiúva (Tapirira guianensis) e do guanandi (Calophyllum brasiliense), que compõem também o estrato superior na TF AVA. 
A Tipologia Florestal Avançada (TF AVA) não teria sido totalmente derrubada, sofrendo apenas retirada seletiva de madeira, apresentando, portanto, idade pouco definida. A fisionomia arbórea é dominante, formando um dossel fechado e relativamente uniforme, com presença de indivíduos emergentes e com diferentes graus de intensidade. O sub-bosque é menos expressivo do que na TF MED, a serapilheira é abundante e as epífitas ocorrem em grande número de espécies e com grande abundância. O sub-bosque é ainda caracterizado fisionomicamente pela guaminhova (Geonoma cf. elegans). A diversidade biológica nessa tipologia é muito grande, apresentando uma complexidade estrutural, podendo a floresta nesse estágio apresentar fisionomia semelhante à da vegetação primária. A diversidade nesta tipologia é muito superior às anteriores. O estrato superior é caracterizado principalmente pela ocorrência de cupiúva (Tapirira guianensis), canela-ponta-de-lança (Ocotea aciphylla), jacarandá-lombriga (Andira anthelminthica), canela-lageana (Ocotea pulchella), palmito (Euterpe edulis), guanandi (Calophyllum brasiliense), guamirim-chorão (Myrcia sp.) e capororocão (Rapanea umbellata). No segundo estrato, as espécies de maior importância são guapiranga (Myrtaceae), palmito (Euterpe edulis), pau-de-macaco (Euphorbiaceae), canela-cinza (Lauraceae), capororoquinha (Ardisia guianensis) e vermelho (Ternstroemia brasiliensis).

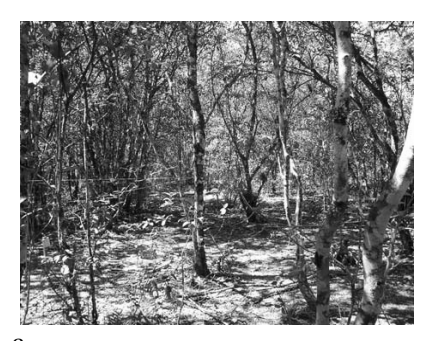

a

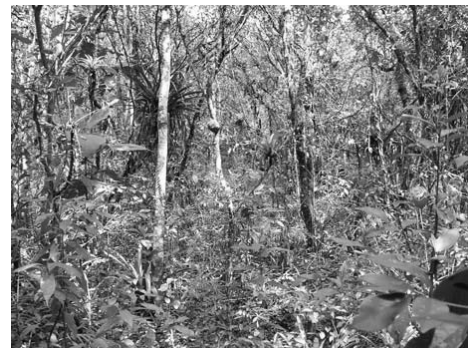

b

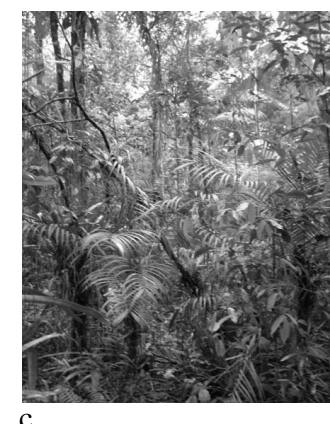

Figura 3. Vista interna das tipologias Inicial (a), Média (b) e Avançada (c) na Floresta Estadual do Palmito, Paranaguá (PR).

Figure 3. Internal view of typologies Initial (a), Medium (b) and Advanced (c) in Palmito State Forest, Paranagua (PR).

Solos

Segundo Wisniewski et al. (1997), todas as áreas estão situadas sobre Espodossolos, no entanto eles apresentam diferença quanto à espessura e à profundidade de ocorrência dos horizontes, e também quanto ao grau de consistência do horizonte $\mathrm{E}$ e quanto à profundidade do lençol freático, o qual se encontra mais próximo da superfície na TF AVA (SCHWARZBACH, 2005).

Tabela 1. Granulometria do horizonte A do solo de tipologias florestais na Floresta Estadual do Palmito, Paranaguá (PR).

Table 1. Texture of the soil A horizon of forests typologies in the Palmito State Forest, Paranagua (PR).

\begin{tabular}{lccc}
\hline Tipologia & Areia & Silte & Argila \\
\hline INI & & -12 & 4 \\
MED & 84 & 12 & 4 \\
AVA & 84 & 19 & 3 \\
\hline
\end{tabular}

Fonte: Wisniewski et al. (1997).

O resultado da análise granulométrica evidencia um solo arenoso, com teores de areia no horizonte superficial $(0-10 \mathrm{~cm})$ variando entre 78 a $84 \%$, dependendo da tipologia considerada (Tabela 1). Nas três tipologias, o pH do solo os caracteriza como ácidos (pH 3,5 na TF INI e pH 3,1 nas TFs MED e AVA). Os teores de carbono são da ordem de 43,9 e 38,7 g.dm ${ }^{-3}$, nas TFs INI e MED, respectivamente, e de $66,8 \mathrm{~g} . \mathrm{dm}^{-3}$ na TF AVA. A saturação por bases varia entre 3,6 e 16,3\% (Tabela 2). A espessura da camada orgânica difere com a idade da floresta. Na TF INI, a espessura varia de 2,98 a 4,85 cm, não havendo diferença significativa entre as espessuras dos horizontes orgânicos. A variação na espessura da camada orgânica na TF MED é de 3,60 a 7,38 cm, com variações significativas dentro dos horizontes de 1,95-2,38 cm para L, 0,90-4,46 cm em F 
e $0,75-0,79 \mathrm{~cm}$ no horizonte $\mathrm{H}$. Na TF AVA, a espessura varia de 3,7 a 7,4 cm, com variações significativas dentro dos horizontes $\mathrm{H}(7,00-13,46 \mathrm{~cm})$ e $\mathrm{F}(2,75-6,63)$ (Tabela 3).

Tabela 2. Características químicas do solo (profundidade $0-5 \mathrm{~cm}$ ) de tipologias florestais na Floresta Estadual do Palmito, Paranaguá (PR).

Table 2. Chemical characteristics of the soil $(0-5 \mathrm{~cm}$ depth) of forests typologies in the Palmito State Forest, Paranagua (PR).

\begin{tabular}{|c|c|c|c|c|c|c|c|c|c|c|c|c|c|}
\hline \multirow{2}{*}{ Tipologia } & \multicolumn{2}{|c|}{ pH } & $\mathrm{Al}^{+3}$ & $\mathbf{H}^{+}+\mathbf{A} \boldsymbol{\ell}^{+3}$ & $\mathrm{Ca}^{+2}$ & $\mathrm{Mg}^{+2}$ & $\mathbf{K}^{+}$ & SB & $\mathbf{T}$ & \multirow{2}{*}{$\begin{array}{c}\mathbf{P} \\
\mathrm{mg} / \mathrm{dm}^{3}\end{array}$} & \multirow{2}{*}{$\begin{array}{c}\mathrm{C} \\
\mathrm{g} / \mathrm{dm}^{3}\end{array}$} & \multirow{2}{*}{$\begin{array}{l}\mathrm{V} \\
\%\end{array}$} & \multirow{2}{*}{$\begin{array}{l}\mathbf{m} \\
\%\end{array}$} \\
\hline & $\mathrm{CaCl}_{2}$ & SMP & \multicolumn{7}{|c|}{$\mathrm{cmol}_{\mathrm{c}} / \mathrm{dm}^{3}$} & & & & \\
\hline INI & 3,5 & 5,4 & 0,7 & 8,5 & 0,9 & 0,7 & 0,1 & 1,7 & 10,2 & 4,1 & 43,9 & 16,3 & 29,8 \\
\hline MED & 3,1 & 5,0 & 1,1 & 11,4 & 0,2 & 0,2 & 0,1 & 0,4 & 11,8 & 3,1 & 38,7 & 3,6 & 72,7 \\
\hline AVA & 3,1 & 4,3 & 1,8 & 23,0 & 1,0 & 0,9 & 0,1 & 2,0 & 25,0 & 5,7 & 66,8 & 8,2 & 48,7 \\
\hline
\end{tabular}

Fonte: Projeto Solobioma (2006). Dados não publicados.

Tabela 3. Espessura do horizonte orgânico e quantidade acumulada de matéria orgânica em tipologias florestais na Floresta Estadual do Palmito, Paranaguá (PR).

Table 3. Thickness of organic horizon and amount of accumulated organic matter in forests typologies in the Palmito State Forest, Paranagua (PR).

\begin{tabular}{lccc}
\hline Tipologia & Inicial & Intermediária & Avançada \\
\hline Espessura $(\mathrm{cm})$ & $2,98-4,85$ & $3,60-7,38$ & $16,67-18,58$ \\
Quantidade $\left(\mathrm{mg}^{-h a}{ }^{-1}\right)$ & 13,1 & 20,12 & 105,91 \\
\hline Fonte: Resende $(2006)$ & & &
\end{tabular}

\section{Procedimentos metodológicos}

Precipitação pluviométrica

A precipitação pluviométrica externa à floresta, ou precipitação total (PT), foi coletada com auxílio de pluviômetro padrão modelo "Ville de Paris", confeccionado em aço inox, instalado em clareira próxima às parcelas florestais. A precipitação interna (PI), água que atravessa o dossel e goteja na superfície do solo, foi monitorada pelo uso de pluviômetros do tipo canaleta, de PVC, com 150 x $11,5 \mathrm{~cm}\left(0,1725 \mathrm{~m}^{2}\right)$, fixos sobre suportes a 1,0 m de altura da superfície do solo e conectados, através de mangueiras, a tambores de plástico (55 litros), onde a água ficava estocada durante o período entre as coletas. As amostragens das soluções (PT e PI) foram realizadas a cada 21 dias, entre junho de 2000 e dezembro de 2004, totalizando quatro anos e meio de estudo. No caso da precipitação total, media-se o volume precipitado com auxílio de uma proveta e retirava-se uma amostra $(125 \mathrm{ml})$ para as posteriores análises químicas. No caso da precipitação interna, media-se a altura da lâmina d'água dentro do tambor e retirava-se também uma amostra para análises. Após a retirada das amostras, pluviômetros e tambores eram escovados e lavados com água deionizada. As amostras foram armazenadas em geladeira, para posteriores análises químicas, que foram realizadas no Laboratório de Biogeoquímica e Nutrição de Plantas (LABINP), no Departamento de Solos e Engenharia Agrícola da Universidade Federal do Paraná, sendo analisados $\mathrm{NO}_{3}^{-}-\mathrm{N}, \mathrm{K}^{+}, \mathrm{Ca}^{2+}, \mathrm{Mg}^{2+} \mathrm{e} \mathrm{Na}^{+}$.
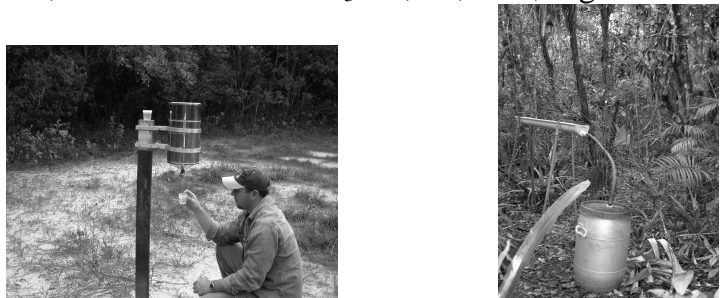

Figura 4. Coletores de precipitação externa e interna na Floresta Estadual do Palmito, Paranaguá (PR).

Figure 4. Collectors of bulk precipitation and throughfall in Pamito State Forest, Paranagua (PR).

A obtenção do volume de PT foi conforme a equação: PT $=0,03017$ X VL, em que PT $=$ precipitação acumulada total $(\mathrm{mm}), \mathrm{VL}=$ volume em litros e 0,03017 é a área do coletor.

Para volume de PI, foi utilizada a seguinte fórmula: $\mathrm{VL}=0,96 \times \mathrm{H}+1,517$, em que $\mathrm{VL}=$ volume em litros e $\mathrm{H}=$ altura da lâmina de água no tambor. 
Uma vez obtido o VL, calculou-se a precipitação interna acumulada $(\mathrm{mm})$, através da seguinte fórmula: Pia = 0,725 x VL, em que Pia = precipitação interna acumulada $(\mathrm{mm})$ e 0,725 é a área do coletor. Para a transformação das concentrações dos elementos em kg.ha ${ }^{-1}$, foi utilizado a seguinte fórmula: $\mathrm{Q}=$ $(\mathrm{c} * \mathrm{~V}) / 100$, em que $\mathrm{Q}=$ quantidade dos elementos $\left(\mathrm{kg} \cdot \mathrm{ha}^{-1}\right), \mathrm{C}=$ concentração de elementos $\left(\mu \mathrm{mol}_{\mathrm{c}} \mathrm{L}^{-1}\right)$ e $\mathrm{V}=$ volume da precipitação $(\mathrm{mm})$.

\section{RESULTADOS E DISCUSSÃO}

Na tabela 4 estão expostos os valores de PT e PI. O ano com maior volume precipitado foi o de 2004, com 3102,4 mm de chuva, e o ano que apresentou menores valores de precipitação foi o de 2003, com $1824 \mathrm{~mm}$. Os maiores valores observados para o ano de 2004 foram um pouco superiores aos obtidos por Nalon; Vellardi (1992), $3068 \mathrm{~mm}$ no ano mais chuvoso, em experimento em floresta secundária pouco degradada, próxima de Cubatão-SP. Britez (1994), trabalhando em áreas de restinga na Ilha do Mel, observou valores de PT de $2262 \mathrm{~mm}$ no segundo ano de experimento, valor muito inferior ao observado no presente estudo, considerando o ano de maior volume precipitado. Scheer (2006), em Floresta Densa Aluvial em regeneração, em Guaraqueçaba (PR), observou valores de 2680 e $2671 \mathrm{~mm}$, respectivamente, para o primeiro e segundo ano. Esses volumes estariam mais próximos aos observados durante o ano de 2002, sendo ainda inferiores aos observados no ano de 2004.

Com exceção do ano de 2001, quando os maiores volumes precipitados foram observados durante o outono, para os demais anos de estudo esse comportamento foi observado durante o verão, com valores muito altos, principalmente no ano de 2002 e 2004. Os menores volumes foram observados durante os invernos de 2001, 2002 e 2004 e na primavera em 2003. Esse comportamento é o mesmo observado para os dados históricos dos últimos 30 anos na região de Paranaguá (Figura 2).

Durante todo o período de estudo, a precipitação que alcançou o piso florestal foi da ordem de $88,4,87,3$ e $80,5 \%$ de PT, respectivamente, para as tipologias INI, MED e AVA. Comparando-se os anos avaliados, 2002 foi o que apresentou maior porcentagem de PI para INI (93,5\%) e MED (90,4\%), e 2004 para AVA (86,4\%). Valores muito inferiores foram obtidos por Meguro; Vinueza; Delitti (1979), em mata secundária na região metropolitana de São Paulo, onde cerca de 68\% de PT alcançou o piso florestal. Valores um pouco superiores aos dos últimos autores foram obtidos por Arcova; Cicco; Rocha (2003), em área de Mata Atlântica, onde se observou 85\% de precipitação interna durante o período chuvoso e $72 \%$ durante o período pouco chuvoso.

A precipitação interna nas três tipologias estudadas apresentou estreita relação com a precipitação total. Foram obtidos coeficientes de determinação $\left(\mathrm{R}^{2}\right)$ altos, explicando que $95 \%, 97 \%$ e 98\% da PI INI, PI MED e PI AVA, respectivamente, podem ser explicados por PT (Figura 5).

Os fluxos dos elementos $\mathrm{N}$ (como nitrato), $\mathrm{K}, \mathrm{Ca}, \mathrm{Mg}$ e Na nas soluções de precipitação externa ou total (PT) e precipitação interna (PI), nas tipologias florestais Inicial (TF INI), Média (TF MED) e Avançada (TF AVA), para diferentes anos de estudo e diferentes estações do ano, são apresentados na tabela 4.

De maneira geral, os fluxos de nutrientes apresentaram a seguinte ordem decrescente de valores:

- PT: $\mathrm{Na}>\mathrm{Ca}>\mathrm{Mg}>\mathrm{K}>\mathrm{NO}_{3}-\mathrm{N}$

- PI INI, PI MED e PI AVA: $\mathrm{Na}>\mathrm{Ca}>\mathrm{K}>\mathrm{Mg}>\mathrm{NO}_{3}-\mathrm{N}$

As quantidades médias de $\mathrm{NO}_{3}-\mathrm{N}, \mathrm{K}, \mathrm{Ca}, \mathrm{Mg}$ e Na em kg.ha ${ }^{-1} \cdot$ ano $^{-1}$ na precipitação externa (PT) foram, respectivamente, 2,$3 ; 5,8 ; 27,3 ; 9,3$ e 73,9. Na TF INI, as quantidades médias depositadas para os mesmos elementos foram 2,5; 7,3; 24,1;8,9 e 60,0 kg.ha ${ }^{-1}$.ano ${ }^{-1}$. Nas TFs MED e AVA, as quantidades médias que alcançaram o piso florestal foram 5,4 e 5,9 $\mathrm{kg} \mathrm{NO}_{3}-\mathrm{N}^{-h a^{-1}}$. ano ${ }^{-1}, 18,4$ e 20,3 kg K.ha ${ }^{-1}$.ano ${ }^{-1}$, 24,0 e 30,1 kg Ca.ha ${ }^{-1}$.ano ${ }^{-1}, 10,6$ e 17,2 kg Mg.ha ${ }^{-1}$.ano ${ }^{-1}$ e 83,0 e 61,1 kg Na.ha ${ }^{-1}$.ano ${ }^{-1}$ (Tabela 4).

Avaliando-se comparativamente os fluxos dos diferentes elementos em PT e PI (Tabela 4), notase certa tendência de fluxos mais elevados de nitrato em PI, sobretudo nas tipologias MED e AVA. Para o potássio, observa-se a mesma tendência do nitrato, e para o magnésio, os maiores fluxos são observados em PI AVA. Cálcio e sódio não mostram grandes diferenças de fluxo entre PT e PI e, dependendo do ano e da tipologia considerada, foram observados, inclusive, fluxos mais altos em PT, o que sugere que parte desses elementos ficou retida no dossel florestal, sendo, possivelmente, absorvida, via foliar, pelas árvores ou retido pelas epífitas, que são numerosas, sobretudo nas tipologias MED e AVA. 

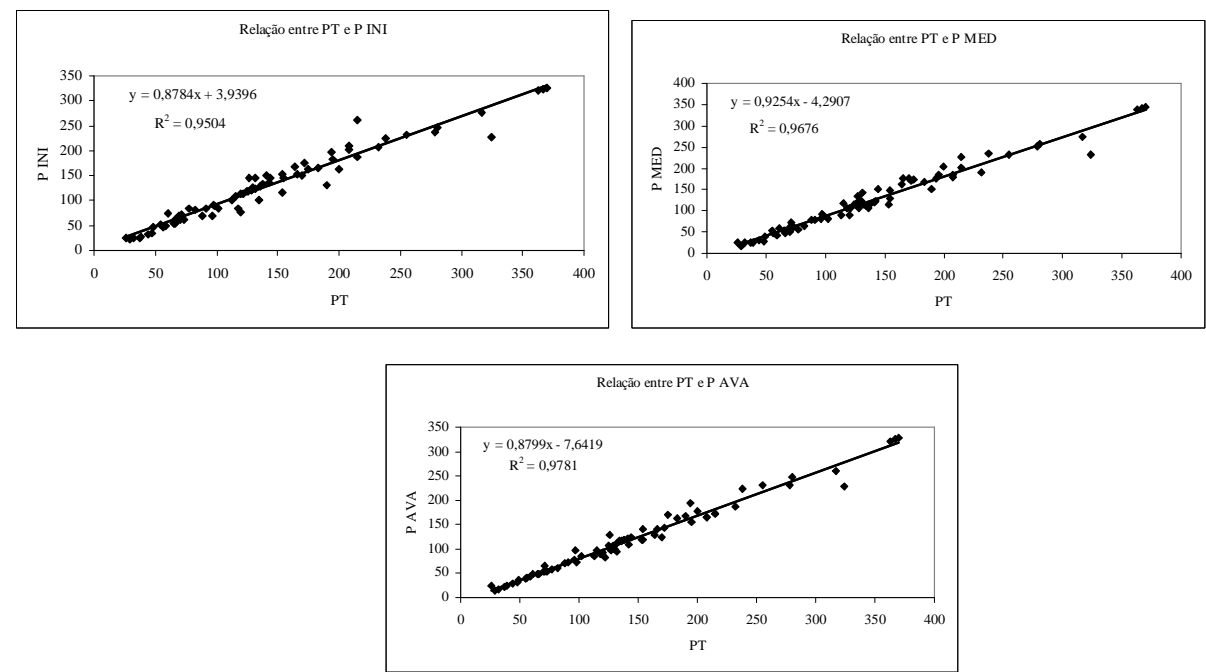

Figura 5. Equações de regressão da precipitação interna (PI) em função da precipitação total (PT) na Floresta Estadual do Palmito.

Figure 5. Regression equations of the throughfall (PI) as a in function of total precipitation (PT) in the Palmito State Forest.

Para $\mathrm{NO}_{3}$ e $\mathrm{K}$, ficou clara a influência da vegetação sobre a quantidade desses elementos. A precipitação externa carregou da atmosfera 2,3 e 5,8 kg.ha ${ }^{-1} \cdot$ ano $^{-1}$, respectivamente, de nitrato e potássio. Após atravessar a cobertura florestal, as quantidades de nitrato lavadas pela chuva foram de 2,5, 5,5 e 5,9 kg.ha ${ }^{-1}$.ano ${ }^{1}$ nas TF INI, TF MED e TF AVA, respectivamente, enquanto que para o potássio foram de 7,3, 18,5 e 20,4 $\mathrm{kg} \mathrm{ha}^{-1} \cdot \mathrm{ano}^{-1}$, nas mesmas tipologias (Tabela 4). Os valores de nitrato são maiores aos encontrados por McDowell (1998) em Floresta Tropical em Porto Rico, e menores aos observados por Protil (2006), também na Floresta Estadual do Palmito. Britez (1994) e Scheer (2006), ambos trabalhando em Mata Atlântica, Meguro et al. (1979) e Arcova; Cicco (1989) encontraram quantidades superiores às do presente estudo. Já Laclau et al. (2003), trabalhando no Congo, observaram valores quantitativos inferiores (Tabela 6).

Cálcio apresentou maiores quantidades médias em PT do que em PI na TF INI e TF MED, sugerindo que a vegetação está absorvendo tal elemento. Os volumes precipitados em ambas as tipologias foram praticamente os mesmos, e isso refletiu nas quantidades de cálcio, registrando-se valores de 24,1 kg.ha ${ }^{-1} \cdot$ ano $^{-1}$ na TF INI e 24,0 kg.ha ${ }^{-1} \cdot$ ano $^{-1}$ na TF MED (Tabela 4). Na TF AVA, as quantidades de $\mathrm{Ca}$ foram superiores àquelas observadas em PT. Nesta tipologia, ocorrem muitos indivíduos da espécie Tapirira guianensis, que apresenta elevados teores desse elemento em seus tecidos e estaria liberando-os por lixiviação (PROTIL, 2006). McDowell (1998) encontrou valores de cálcio próximos aos observados nas TF INI e TF MED. Scheer (2006), trabalhando também em Floresta Atlântica, e Protil (2006), trabalhando nas mesmas áreas do presente estudo, porém utilizando metodologia de coleta diferente, encontraram quantidades inferiores às observadas nas três tipologias estudadas (Tabela 6).

O magnésio, mesmo apresentando uma pequena diferença, assim como cálcio, mostrou maiores quantidades em PT na TF AVA que na TF INI (Tabela 4). Os valores quantitativos foram aumentando da TF INI para a TF AVA, sendo observada influência da vegetação sobre o magnésio lavado/lixiviado das copas das árvores. As quantidades que alcançaram o piso florestal foram de $8,88 \mathrm{~kg} \cdot \mathrm{ha}^{-1} \cdot \mathrm{ano}^{-1} \mathrm{na}$ TF INI, de 10,6 kg ha ${ }^{-1}$.ano ${ }^{-1}$ na TF MED e de 17,2 kg.ha ${ }^{-1} \cdot$ ano $^{-1}$ na TF AVA, valor esse duas vezes maior que o observado na TF INI. As quantidades de magnésio observadas nas TF MED e TF AVA foram semelhantes às relatadas por Britez (1994) e McDowell (1998), enquanto Protil (2006) observou valores semelhantes aos observados nas TFs INI e MED.

Durante o período de estudo, a quantidade média anual de sódio que entrou pela precipitação total (PT) na Floresta do Palmito foi de $73,9 \mathrm{~kg} \cdot \mathrm{ha}^{-1} \cdot \mathrm{ano}^{-1}$. A quantidade desse elemento nas TF INI e TF AVA foi menor $\left(60,0\right.$ e $61,1 \mathrm{~kg} \cdot \mathrm{ha}^{-1} \cdot$ ano $^{-1}$, respectivamente), o que pode sugerir, como já mencionado anteriormente para $\mathrm{Ca}$, que a vegetação esteja absorvendo sódio. Já na TF MED, observa-se um aumento na quantidade de sódio (Tabela 4). Esse comportamento já foi observado nos valores qualitativos desse elemento. Pinto (2001), trabalhando na mesma área de estudo, avaliando a contribuição de espécies 
arbóreas para a ciclagem de nutrientes, através de lixiviação de folhas verdes coletadas nas copas das árvores, observou o mesmo comportamento para o sódio. Em termos quantitativos, valores semelhantes ao deste estudo foram relatados por McDowell (1998), enquanto Scheer (2006) e Protil (2006) reportaram valores muito superiores aos das três tipologias.

Tabela 4. Fluxos estacionais de elementos pela precipitação total e pela precipitação interna, em tipologias florestais na Floresta Estadual do Palmito, Paranaguá (PR).

Table 4. Seasonal fluxes of elements by bulk precipitation and throughfall in forests typologies in the Palmito State Forest, Paranagua (PR).

\begin{tabular}{|c|c|c|c|c|c|c|c|c|}
\hline & Ano & Estação & Vol. chuva $(\mathbf{m m})$ & $\mathrm{NO}_{3}-\mathrm{N}$ & $\mathbf{K}$ & $\mathrm{Ca}$ & Mg & $\mathbf{N a}$ \\
\hline \multirow{21}{*}{ PT } & & verão & 625,58 & 0,09 & 1,40 & 1,10 & 0,89 & 18,64 \\
\hline & & outono & 765,40 & 0,29 & 1,65 & 2,67 & 0,61 & 11,80 \\
\hline & & inverno & 297,63 & 0,22 & 1,10 & 1,18 & 1,02 & 12,03 \\
\hline & & primavera & 565,20 & 0,20 & 2,26 & 2,64 & 1,36 & 17,89 \\
\hline & 2001 & & 2253,81 & 0,80 & 6,42 & 7,60 & 3,87 & 60,36 \\
\hline & & verão & 1014,00 & 0,38 & 2,16 & 9,27 & 4,66 & 34,19 \\
\hline & & outono & 496,70 & 0,27 & 2,69 & 8,92 & 4,12 & 17,41 \\
\hline & & inverno & 263,68 & 0,11 & 1,17 & 4,79 & 1,29 & 6,29 \\
\hline & & primavera & 672,95 & 0,28 & 1,94 & 10,31 & 2,72 & 13,71 \\
\hline & 2002 & & 2447,33 & 1,04 & 7,96 & 33,29 & 12,78 & 71,59 \\
\hline & & verão & 832,98 & 0,62 & 2,76 & 19,56 & 4,25 & 33,39 \\
\hline & & outono & 396,56 & 0,27 & 1,30 & 8,28 & 1,70 & 9,41 \\
\hline & & inverno & 373,08 & 0,30 & 1,02 & 6,08 & 1,35 & 10,50 \\
\hline & & primavera & 221,67 & 0,13 & $\mathrm{dp}$ & 3,50 & 0,91 & 8,67 \\
\hline & 2003 & & 1824,29 & 1,32 & 5,07 & 37,41 & 8,21 & 61,97 \\
\hline & & verão & 1205,87 & 0,98 & 0,11 & 5,24 & 1,28 & 19,54 \\
\hline & & outono & 680,56 & 2,94 & 0,64 & 5,59 & 0,77 & 23,42 \\
\hline & & inverno & 501,49 & 1,29 & 0,80 & 12,95 & 4,32 & 24,84 \\
\hline & & primavera & 714,46 & 0,84 & 2,24 & 7,29 & 6,07 & 33,97 \\
\hline & 2004 & & 3102,39 & 6,06 & 3,79 & 31,07 & 12,45 & 101,77 \\
\hline & & MÉDIA & 2406,96 & 2,31 & 5,81 & 27,35 & 9,33 & 73,93 \\
\hline \multirow{17}{*}{ INI } & & verão & 578,71 & 1,81 & 2,90 & 2,30 & 1,00 & 18,64 \\
\hline & & outono & 703,08 & 1,65 & 2,16 & 2,44 & 0,97 & 11,80 \\
\hline & & inverno & 266,13 & 0,26 & 2,35 & 1,52 & 1,38 & 12,03 \\
\hline & & primavera & 519,54 & 0,67 & 5,74 & 2,95 & 2,19 & 17,89 \\
\hline & 2001 & & 2067,46 & 4,38 & 13,16 & 9,22 & 5,55 & 60,36 \\
\hline & & verão & 1012,32 & 0,53 & 2,96 & 15,47 & 5,90 & 34,70 \\
\hline & & outono & 455,35 & 0,32 & 1,89 & 5,82 & 2,94 & 15,63 \\
\hline & & inverno & 223,93 & 0,21 & 1,18 & 4,16 & 1,16 & 5,73 \\
\hline & & primavera & 607,91 & 0,46 & 4,20 & 13,00 & 4,51 & 17,97 \\
\hline & 2002 & & 2299,51 & 1,51 & 10,23 & 38,46 & 14,51 & 74,02 \\
\hline & & verão & 707,23 & 0,14 & 0,84 & 12,52 & 2,18 & 6,62 \\
\hline & & outono & 389,12 & 0,14 & 0,72 & 6,19 & 1,19 & 6,58 \\
\hline & & inverno & 291,12 & 0,41 & 1,55 & 7,49 & 1,50 & 11,47 \\
\hline & & primavera & 201,57 & 0,15 & $\mathrm{dp}$ & 4,37 & 1,13 & 7,74 \\
\hline & 2003 & & 1589,05 & 0,84 & 3,11 & 30,57 & 6,00 & 32,41 \\
\hline & & verão & 1079,79 & 0,50 & 0,13 & 8,74 & 1,80 & 20,50 \\
\hline & & outono & 607,02 & 1,13 & 0,11 & 2,04 & 0,84 & 11,96 \\
\hline
\end{tabular}




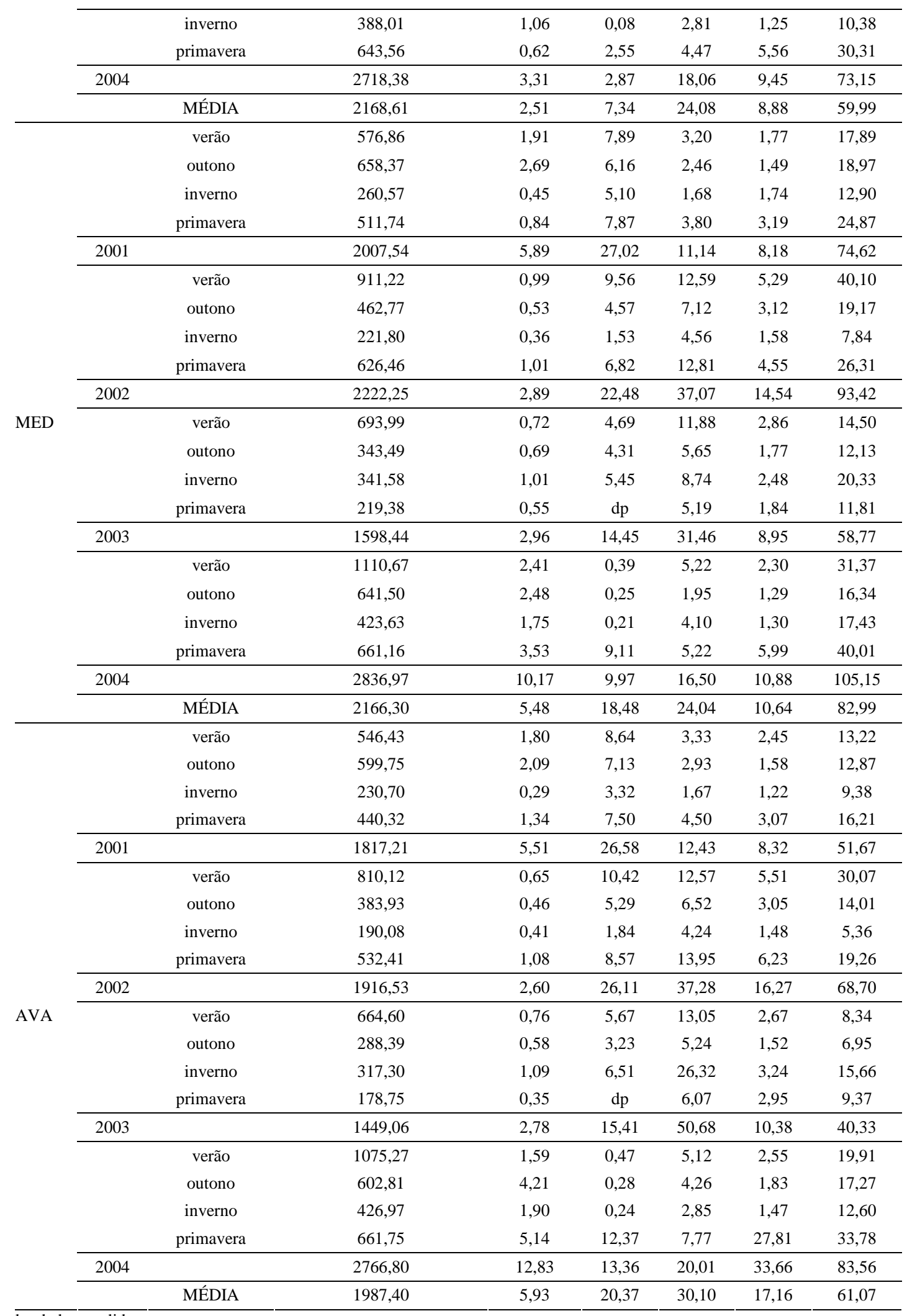

$\overline{\mathrm{dp}: \text { dados }} \overline{\text { perdidos }}$ 
Com relação ao efeito estacional dos fluxos dos nutrientes nas soluções de precipitação, os dados mostram pouca clareza. Isso porque os fluxos seriam dependentes de muitos fatores que, segundo Arcova; Cicco; Shimomichi (1993) afetam a composição química da água da chuva, como variação na quantidade, intensidade e distribuição das precipitações, alterações na trajetória de massas de ar e contribuição de diferentes fontes injetoras de íons na atmosfera. Entretanto, correlações positivas e significativas entre volume precipitado e quantidade dos elementos (Tabela 5) foram detectadas, ou seja, os maiores volumes de chuva proporcionaram maior quantidade dos elementos nas soluções de precipitação. Esse comportamento foi mais expressivo nas TF MED e TF AVA. Como a vegetação nessas duas tipologias é mais complexa e diversa, a captura dos elementos da atmosfera deve ser superior e resulta numa maior liberação deles durante os eventos de precipitação. Cabe ressaltar também que, para alguns elementos, pode estar ocorrendo a sua lixiviação das partes internas das plantas.

Tabela 5. Coeficientes de correlação de Spearman entre quantidade dos elementos e volume precipitado em PT, TF INI, TF MED e TF AVA, na Floresta Estadual do Palmito, Paranaguá (PR).

Table 5. Spearman correlation coefficients between the elements quantity and precipitated volume in PT, TF INI, TF MED and TF AVA, in the Palmito State Forest, Paranagua (PR).

\begin{tabular}{lcccc}
\hline & PT $(\mathbf{n}=\mathbf{7 4})$ & PI INI $(\mathbf{n}=\mathbf{7 4})$ & PI MED $(\mathbf{n}=\mathbf{7 4})$ & PI AVA $(\mathbf{n}=\mathbf{7 4})$ \\
\hline $\mathrm{N}^{-\mathrm{NO}_{3}}{ }^{-}$ & $0,31^{* *}$ & $0,24^{* *}$ & $0,53^{* *}$ & $0,59^{* *}$ \\
$\mathrm{~K}$ & $0,31^{* *}(\mathrm{n}=68)$ & $0,17(\mathrm{n}=71)$ & $0,39^{* *}(\mathrm{n}=71)$ & $0,37 * *(\mathrm{n}=71)$ \\
$\mathrm{Ca}$ & $0,35^{* *}$ & $0,51^{* *}$ & $0,57^{* *}$ & $0,47^{* *}$ \\
$\mathrm{Mg}$ & $0,29^{* *}$ & $0,40^{* *}$ & $0,47^{* *}$ & $0,39^{* *}$ \\
$\mathrm{Na}$ & $0,39^{* *}$ & $0,51^{* *}$ & $0,68^{* *}$ & $0,61^{* *}$ \\
\hline
\end{tabular}

Na tabela 5, podem ser observados maiores coeficientes de correlação para a precipitação interna do que para a precipitação externa, e a correlação é positiva, o que reforça a hipótese da lavagem/lixiviação dos elementos capturados da atmosfera (ou das partes internas das plantas) pela chuva. É interessante notar também que, para elementos reconhecidamente de origem atmosférica $(\mathrm{N}, \mathrm{Ca}$, $\mathrm{Mg}$ e $\mathrm{Na}$ ), os coeficientes de correlação são mais elevados quando comparados ao elemento K, que é reconhecidamente extraído da vegetação por lixiviação (MARQUES; RANGER, 1997). Esses dados sugerem que, no presente caso, o volume precipitado influenciou mais diretamente a lavagem do que a lixiviação dos nutrientes do dossel florestal.

Tabela 6. Quantidade de elementos minerais $\left(\mathrm{kg} \cdot \mathrm{ha}^{-1} \cdot \mathrm{ano}^{-1}\right)$ na precipitação interna em diferentes ecossistemas florestais.

Table 6. Quantity of mineral elements $\left(\mathrm{kg} \cdot \mathrm{ha}^{-1} \cdot \mathrm{ano}^{-1}\right)$ in throughfall in different forest ecosystems.

\begin{tabular}{|c|c|c|c|c|c|c|c|c|}
\hline LOCAL & \multicolumn{2}{|c|}{ ECOSSISTEMA } & $\mathrm{NO}_{3}-\mathrm{N}$ & $\mathbf{K}$ & $\mathbf{C a}$ & Mg & $\mathbf{N a}$ & REFERÊNCIA \\
\hline São Paulo & \multicolumn{2}{|l|}{ FMS } & nd & 126,00 & nd & nd & nd & MEGURO et al., 1979 \\
\hline São Paulo & \multicolumn{2}{|l|}{ Cerrado } & nd & 67,80 & 6,80 & 7,10 & 0,00 & LIMA, 1986 \\
\hline São Paulo & \multicolumn{2}{|l|}{ FS } & nd & 79,80 & 11,50 & 7,20 & 20,65 & ARCOVA e CICCO, 1989 \\
\hline \multirow{2}{*}{ Paraná } & \multirow{2}{*}{ F. Atlântica } & Restinga baixa & nd & 44,80 & 12,10 & 14,20 & nd** & \multirow{2}{*}{ BRITEZ, 1994} \\
\hline & & \multirow[t]{2}{*}{ Restinga alta } & nd & 49,90 & 11,40 & 14,60 & nd** & \\
\hline Porto Rico & F.Tropical & & 0,2 & 51,6 & 22,7 & 13,14 & 81,30 & McDOWELL, 1998 \\
\hline \multirow{2}{*}{ Congo } & \multirow{2}{*}{ Savana } & Savana & nd & 2,80 & 3,30 & 1,40 & nd** & \multirow{2}{*}{ LACLAU et al., 2003} \\
\hline & & Eucalyptus & nd & 6,80 & 7,80 & 3,20 & $\mathrm{nd}^{* *}$ & \\
\hline \multirow{2}{*}{ Paraná } & \multirow{2}{*}{ F. Atlântica } & Capoeira aluvial & nd & 51,60 & 4,90 & 2,90 & 95,80 & \multirow{2}{*}{ SCHEER, 2006} \\
\hline & & FODSM & nd & 28,60 & 4,20 & 2,10 & 91,80 & \\
\hline \multirow{3}{*}{ Paraná } & \multirow{3}{*}{ F. Atlântica } & Tipologia inicial & 3,50 & 25,20 & 13,70 & 7,60 & 127,30 & \multirow{3}{*}{ PROTIL, 2006} \\
\hline & & Tipologia média & 9,30 & 55,90 & 15,30 & 10,60 & 148,50 & \\
\hline & & Tipologia avançada & 14,50 & 73,10 & 17,40 & 8,20 & 155,08 & \\
\hline \multirow{3}{*}{ Paraná } & \multirow{3}{*}{ F. Atlântica } & Tipologia inicial & 2,51 & 7,34 & 24,08 & 8,88 & 59,99 & \multirow{3}{*}{ Presente estudo } \\
\hline & & Tipologia média & 5,48 & 18,48 & 24,04 & 10,64 & 82,99 & \\
\hline & & Tipologia avançada & 5,93 & 20,37 & 30,10 & 17,16 & 61,07 & \\
\hline
\end{tabular}

FMS: Floresta Mesófila Secundária; nd: não determinado; FS: Floresta secundária; FODSM: Floresta Ombrófila Densa Submontana. 
Em PT, os dados (Tabela 4) mostram uma tendência de maiores valores de fluxos nas estações com maior volume precipitado. Isso ficou mais marcado nos anos em que a precipitação foi bastante distinta entre as estações, como é o caso dos anos de 2002 e 2003, quando, no verão, o volume precipitado foi superior ao observado nas demais estações, o que resultou também em maiores fluxos de nutrientes. Por outro lado, em 2004 isso não ocorreu, provavelmente pelo fato de a primavera de 2003, que antecedeu o verão de 2004, ter também apresentado volumes expressivos de precipitação, o que teria contribuído para uma diminuição da quantidade de elementos em suspensão na atmosfera.

Em PI, independentemente da tipologia florestal, o efeito estacional se caracterizou por uma tendência de maiores fluxos de nutrientes no verão e na primavera (Tabela 4), que são, normalmente, as duas estações com maiores precipitações e maior incidência de ventos, apesar de não ter sido sempre o caso nos anos de estudo deste trabalho. Os ventos podem ter papel importante nesses fluxos, pois seriam responsáveis pelo transporte de partículas de aerossóis, ou outras em suspensão na atmosfera, as quais seriam depositadas sobre o dossel da floresta (CARVALHO JÚNIOR, 2005; MELLO; MOTTA, 1987; LACLAU et al., 2003). Infelizmente, os dados de vento da estação meteorológica de Paranaguá não foram ainda obtidos, o que ajudaria a compreensão de sua importância sobre esses fluxos de nutrientes.

\section{CONCLUSÕES}

- O volume de PT avaliado durante o período de estudo é compatível com os observados para os dados dos últimos 30 anos na região de Paranaguá.

- Na região estudada, as soluções de precipitação contribuem com quantidades expressivas de sódio e cálcio aos ecossistemas florestais, mas também mostram contribuição considerada de potássio e magnésio, sendo esse comportamento explicado pela proximidade das parcelas de estudo ao oceano.

- A interação com vegetação se traduziu pela retenção de elementos como Ca e Na no dossel florestal (absorção foliar ou captura pelas epífitas), mas também pela lavagem destes e dos demais elementos, enriquecendo em nutrientes a solução que chega ao solo. Essa interação é difícil de ser generalizada, devido à complexidade dos ecossistemas estudados.

- Com relação ao aporte dos nutrientes avaliados nos diferentes anos de estudo, e para todas as soluções, observou-se que os fluxos variaram de um ano para outro.

- Tanto nas soluções de PT quanto de PI, a quantidade de chuva teve influência significativa sobre a lavagem de nitrato, cálcio, magnésio e sódio das copas das árvores.

\section{AGRADECIMENTOS}

Os autores agradecem ao Conselho Nacional de Desenvolvimento Científico e Tecnológico (CNPq) e ao Ministério Federal da Educação e Pesquisa da Alemanha (BMBF), pelo auxílio financeiro ao projeto Solobioma (www.solobioma.ufpr.br) e também pelas bolsas de pesquisa cedidas.

Agradecem também ao técnico de campo, Wilson Saran, pela coleta de amostras das soluções e pela manutenção das áreas experimentais.

\section{REFERÊNCIAS}

ARCOVA, F. C. S.; CICCO, V. de. Fluxo de nutrientes através da precipitação interna e escoamento pelo tronco em floresta natural secundária no Parque Estadual da Serra do Mar - Núcleo Cunha - SP. Boletim Técnico do Instituto Florestal, São Paulo, v. 41, n. 1, p. 37-58, 1987.

ARCOVA, F. C. S.; CICCO, V. de; SHIMOMICHI, P. Y. Qualidade da água e dinâmica dos nutrientes em bacia hidrográfica recoberta por floresta de Mata Atlântica. Revista do Instituto Florestal, São Paulo, v. 5, n. 1, p. 1-20, 1993.

BLUM, W. E. H. Ecossistemas florestais: ciclo de bioelementos. Floresta: Curitiba, v. 9, n. 1, p. 39-50, 1978.

BRITEZ, R. M. Ciclagem de nutrientes minerais em duas florestas da planície litorânea da Ilha do Mel, Paranaguá, PR. 240 f. Dissertação (Mestrado em Engenharia Florestal) - Setor de Ciências Agrárias, Universidade Federal do Paraná, Curitiba, 1994. 
CAMPOS, M. L.; MARCHI, G.; LIMA, D. M.; SILVA, C. A. S. Ciclagem de nutrientes em florestas e pastagens. Lavras: UFLA, s.d. 61 p.

CARVALHO JR., V. N. de. Deposição atmosférica e composição química da água de chuva. Revista Tecnológica Fortaleza, Fortaleza, v. 25, n. 2, p. 61-71, 2005.

HAAG, H. P. Ciclagem de Nutrientes em florestas tropicais. Campinas: Fundação CARGIL, 1985.

INSTITUTO BRASILEIRO DE GEOGRAFIA E ESTATÍSTICA (IBGE). Manual técnico da vegetação brasileira. Rio de Janeiro, 1992. 92 p. (Série Manuais Técnicos em Geociências, n.1).

LACLAU, J. P.; RANGER, J.; NZILA, J. P.; DELEPORTE, P. Nutrient cycling in a clonal stand of Eucalyptus and na adjacent savanna ecosystem in Congo. 2. Chemical composition of soil solutions. Forest Ecology and Management. v. 180, p. 527-544, 2003.

MARQUES, R.; RANGER, J. Nutrient dynamics in a chronosequence of Douglas-fir (Pseudotsuga menziesii (Mirb.) Franco) stands on the Beaujolais Mounts (France). 1- Qualitative approach. Forest Ecology and Management, Amsterdam, v. 91, p. 255-277, 1997.

McDOWELL, W. H. Internal nutrient fluxes in a Puerto Rican rain forest. Journal of Tropical Ecology, Cambrigde, v. 14, p. 521-536. 1998.

MEGURO, M.; VINUZA, G. N.; DELITTI, W. B. C. Ciclagem de nutrientes na mata mesófila secundária - São Paulo. II - O papel da precipitação na importação e transferência de potássio e fósforo. Boletim de Botânica, São Paulo, v. 7, p. 61-67, 1979.

MELlO, W. Z.; MOTTA, J. S. T. Acidez na chuva. Ciência Hoje, Rio de Janeiro, v. 6, n. 34, p. 40-43. 1987.

PINTO, C. B. Contribuição de Espécies Arbóreas para a Ciclagem de Nutrientes em Sucessão Vegetal na Floresta Ombrófila Densa das Terras Baixas. 68 f. Dissertação (Mestrado em Conservação da Natureza) - Setor de Ciências Agrárias, Universidade Federal do Paraná, Curitiba, 2001.

POGGIANI, F. Alterações dos ciclos biogeoquímicos em florestas. In: CONGRESSO NACIONAL SOBRE ESSENCIAS NATIVAS, 2, São Paulo. Revista do Instituto Florestal, São Paulo, v. 4, p. 734-739, 1992.

PROTIL, C. Z. Contribuição de quatro espécies arbóreas ao ciclo biogeoquímico em Floresta Atlântica na Planície Litorânea do Paraná. 128 f. Tese (Doutorado em Conservação da Natureza)) Setor de Ciências Agrárias, Universidade Federal do Paraná, Curitiba, 2006.

RESENDE, D. C. Horizontes orgânicos sob Floresta Ombrófila Densa no Litoral Paranaense. Dissertação (Mestrado em Ciência do Solo) - Setor de Ciências Agrárias, Universidade Federal do Paraná, Curitiba, 2007.

RODERJAN, C. V.; GALVÃO, F.; KUNYOSHI, Y. S.; HATSCHBACH, G. As unidades fitogeográficas do Estado do Paraná. Ciência \& Ambiente, Santa Maria, RS, n. 24, p. 75-92, 2002.

SCHEER, M. B. Ciclagem de nutrientes em um trecho de Floresta Ombrófila Densa Aluvial em regeneração, Guaraqueçaba, PR. 155 f. Dissertação (Mestrado em Conservação da Natureza) - Setor de Ciências Agrárias, Universidade Federal do Paraná, Curitiba, 2006.

SCHWARZBACH, J. Dinâmica química da solução do solo em três fases sucessionais da Floresta Ombrófila Densa das Terras Baixas no Litoral do Paraná. Dissertação (Mestrado em Ciência do Solo) - Setor de Ciências Agrárias, Universidade Federal do Paraná, Curitiba, 2005.

TUKEY JR, H. B. The leaching of substances from plants. Annual Review of Plant Physiology, Palo Alto, v.21, p. 305-329, 1970.

WISNIEWSKI, C.; ZILLER, S. R.; CURCIO, G. R.; RACHWAL, M. F. G.; TREVISAN, E.; SOUZA, J. $P$. Caracterização do ecossistema e estudo das relações solo cobertura vegetal em planície pleistocênica do litoral paranaense. Curitiba, 1997, 55 p. CNPq. Projeto Integrado Relatório Fl. 